\title{
Angiographic analysis of normal coronary artery lumen diameter in a Turkish population*
}

\author{
Ozan Turamanlar ${ }^{1}$, Fahri Adalı ${ }^{2}$, Mehtap Beker Acay ${ }^{3}$, Erdal Horata ${ }^{1}$, Onur Tor ${ }^{4}$, Oğuzhan Macar, \\ Hülya Keş ${ }^{4}$ Hakan Keskin ${ }^{4}$, Yasin Abbasoğlu ${ }^{4}$ \\ ${ }^{1}$ Department of Anatomy, Faculty of Medicine, Afyon Kocatepe University, Afyonkarabisar, Turkey \\ ${ }^{2}$ Department of Cardiovascular Surgery, Faculty of Medicine, Afyon Kocatepe University, Afyonkarabisar, Turkey \\ ${ }^{3}$ Department of Radiology, Faculty of Medicine, Afyon Kocatepe University, Afyonkarabisar, Turkey \\ ${ }^{4}$ Medical Student, Faculty of Medicine, Afyon Kocatepe University, Afyonkarahisar, Turkey
}

\begin{abstract}
Objectives: Cardiovascular diseases are the cause of nearly half of deaths in Turkey. Coronary artery diameters affect the procedure and outcome of coronary by-pass operations. The aim of this study was to measure the coronary artery diameters of the individuals with normal coronary artery on angiographic images to assess to provide data for a normal Turkish population and compare the results with studies from other countries.

Methods: Seventy-seven male and female individuals between 31-79 years old were used in the study. Diameters of the two coronary arteries and their branches were measured in four segments using the Image J program.

Results: The mean diameters of major coronary arteries i.e. LMCA, LAD, Cx and RCA were measured as $4.43 \pm 0.76 \mathrm{~mm}$, $3.48 \pm 0.53 \mathrm{~mm}, 3.11 \pm 0.67 \mathrm{~mm}$ and $3.45 \pm 0.50 \mathrm{~mm}$, respectively.

Conclusion: This study revealed that the coronary artery lumen diameters of the Turkish population were parallel with the study conducted in the Iraqi population especially. A statistically significant correlation between certain coronary artery diameters were demonstrated also found. The findings of this study will contribute to the diagnosis and the treatment methods for the patients.
\end{abstract}

Keywords: coronary angiography; diameter; morphometry

Anatomy 2016;10(2):99-104 @2016 Turkish Society of Anatomy and Clinical Anatomy (TSACA)

\section{Introduction}

With its increasing incidence, coronary artery disease is one of the most common causes of morbidity and mortality especially in the industrialized countries, accounting for more than one-third of total deaths. Cardiovascular diseases are the cause of almost half of the deaths in Turkey. Amongst the European Union countries, Turkey is the fourth in the mortality caused by cardiovascular diseases in men and the first in women. ${ }^{[1,2]}$ Coronary artery diameters are one of the most important factors that affect the technique and outcome of coronary by-pass operations. ${ }^{[3]}$

Coronary arteries arise from the aorta as two branches, the right coronary artery (RCA) and the left main coro- nary artery (LMCA). After a short distance, the LMCA divides into two, and gives the left anterior descending (LAD) and circumflex artery (Cx) branches. While LAD runs along the anterior interventricular sulcus down towards the apex, $\mathrm{Cx}$ artery runs along the atrioventricular groove, giving rise to the left marginal branch. The circumflex then continues around the heart, terminating on its posteroinferior aspect, to supply blood to both the left and right atrium. ${ }^{[4]}$

Lumen diameter of normal human coronary arteries and several factors affecting their lumen diameters have previously been studied in different countries on different populations. ${ }^{[5-10]}$ To the best of our knowledge, there is no study with international recognition regarding normal

*This study has been presented as a poster at the XXIV International Symposium on Morphological Sciences (ISMS) in Istanbul, Turkey in 2015. 
coronary artery diameters in Turkish population. The aim of this study was to measure the coronary artery diameters of the individuals with normal coronary arteries on angiographic images, to assess the association among the different diameter values as well as the effect of age and the gender on the diameters, and finally compare our results with those from other populations.

\section{Materials and Methods}

This retrospective clinical study was performed after approval of the Ethics Committee of Afyon Kocatepe University, Faculty of Medicine. Since elective angiography for normal coronary arteries is assumed as unethical, the actual values of any population can not be obtained by this method. Therefore, images from 77 patients who were admitted to Afyon Kocatepe University Hospital and had normal angiographic values were used in this study. Coronary angiography was performed using a Siemens Axiom Artis (Siemens AG, Muenchen, Germany) angiography device. Diameters of both two coronary arteries and the branches were measured in the following segments:

- Medial part of the distance where LMCA arises at the level of aorta to the area that $\mathrm{Cx}$ and the LAD appear

- Medial part of the distance from the beginning of the LAD to the region where the diagonal branch 1 leaves

- Medial part of the distance from the beginning of $\mathrm{Cx}$ to the part where obtuse marginal branch 1 leaves

- Proximal part of the distance between where the RCA starts at the level of aorta and the acute marginal branch

Images were transferred to Image J Version 1.49 for Windows (National Institutes of Health, Bethesda, MD, USA) software and coronary arteries were measured using the catheter diameter (2 mm) as a reference (Figures 1-4). Groups were formed according to the age and the gender. The results were compared with those of the previous studies.

Kolmogorov-Smirnov test was used to verify the normal distribution of variables, and Mann-Whitney $U$ test was used to compare differences between two independent groups. Statistical analysis was performed using SPSS for Windows version 20.0 (SPSS Inc., Chicago, IL, USA). All values were presented as mean \pm standard deviation (SD). A p value of less than 0.05 was considered statistically significant.

\section{Results}

A total of 77 individuals, 26 (34\%) males and 51 (66\%) females were included in the study. The age range was between 31 and 79 years and the mean age was 56 years

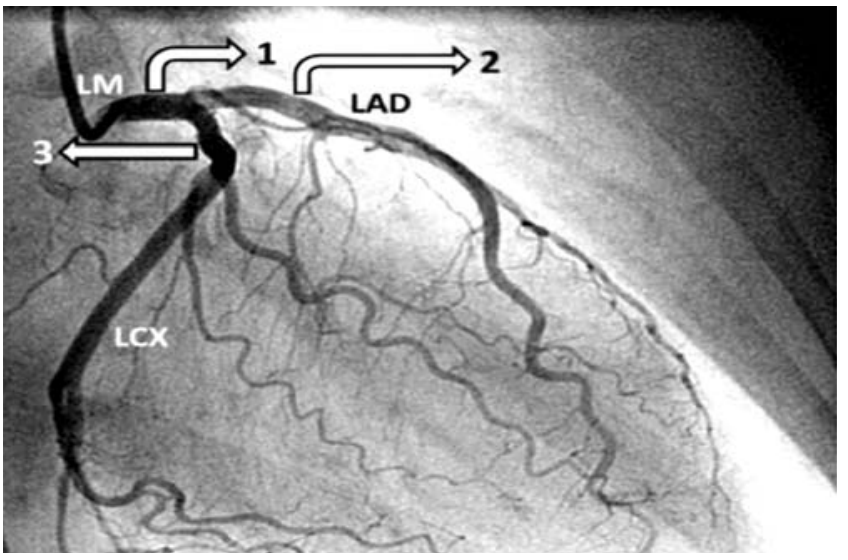

Figure 1. Angiographic view of the left coronary artery. 1 (LM): left main coronary artery; 2 (LAD): left anterior descending artery; 3 (LCX): circumflex artery.

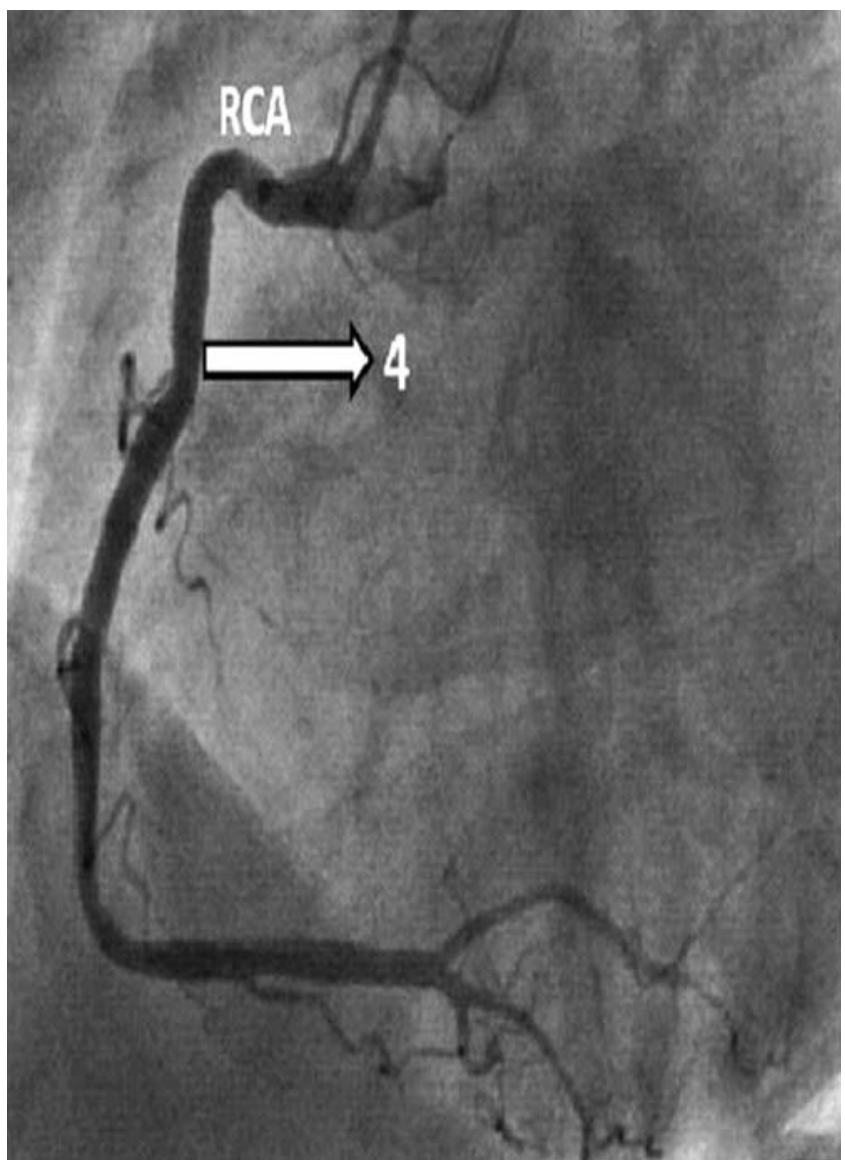

Figure 2. Angiographic view of the right coronary artery. 4 (RCA): right coronary artery.

in males and 57 years in females. The mean age was 57 years in the whole study group. Mean values of coronary artery lumen diameter according to gender are shown in 


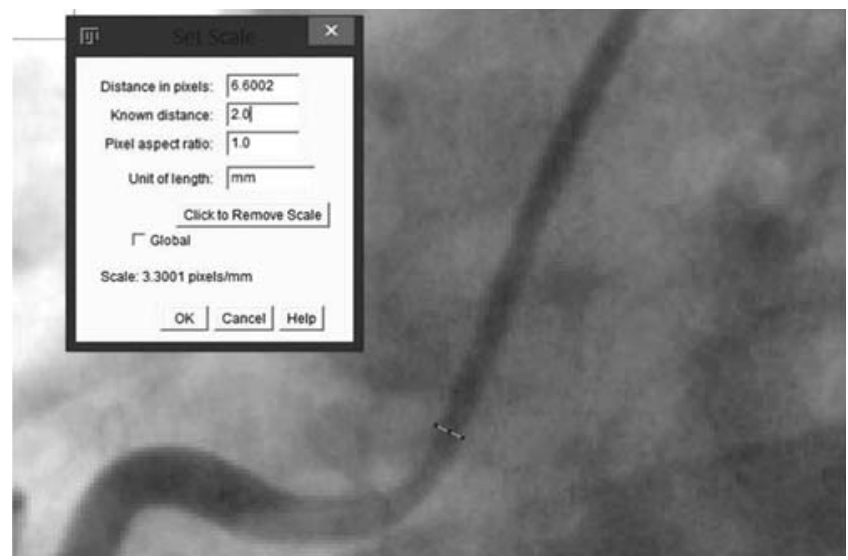

Figure 3. Calibration of the coronary arteries by using Image J program.

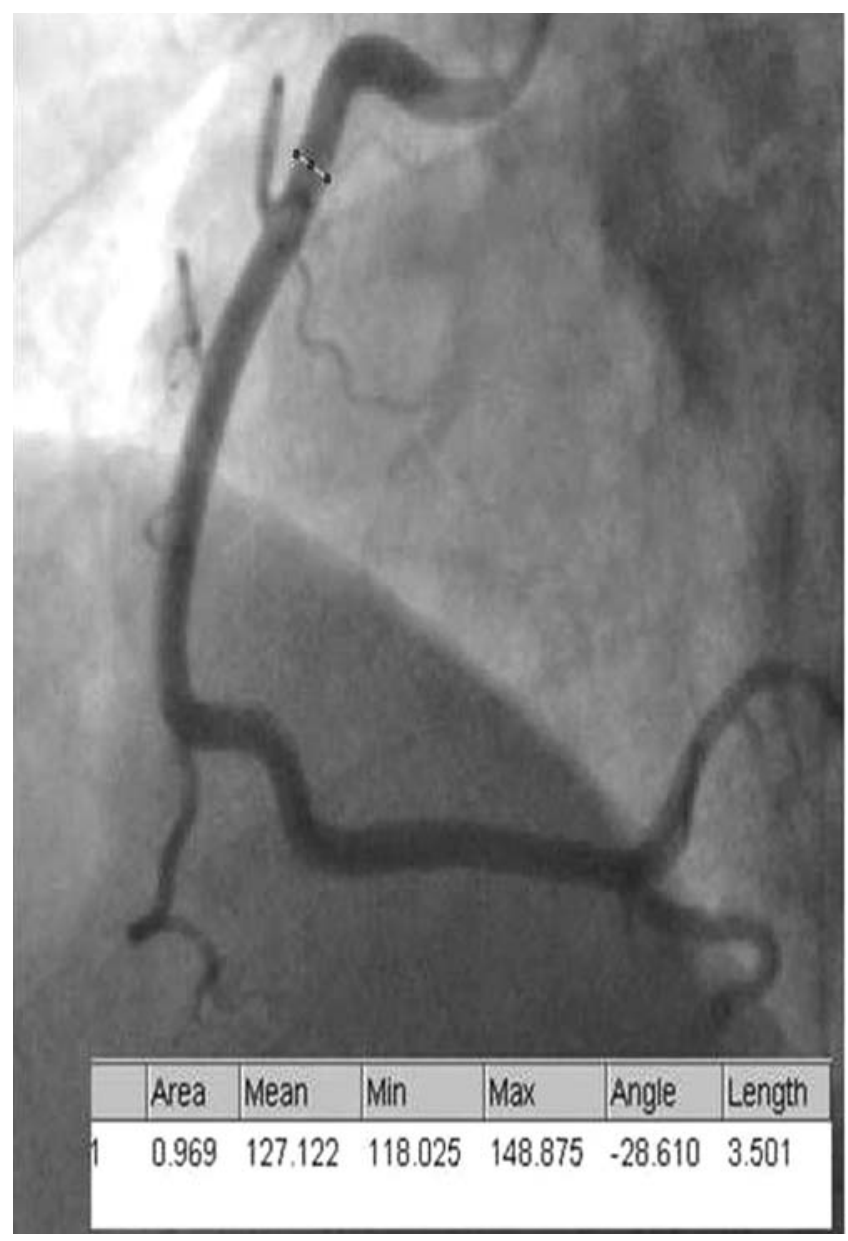

Figure 4. Calculation of coronary artery diameter by using Image J program.

Table 1. Mean values of males were higher than women. However, only mean value of the LAD was found statistically significant between the genders $(\mathrm{p}=0.034)$. Mean values of coronary artery lumen diameter according to decades are shown in Table 2. Only mean value of the $\mathrm{Cx}$ artery was found statistically significant between the decades $(\mathrm{p}=0.008)$.

\section{Discussion}

Coronary artery diameters vary in the normal population. Several studies have demonstrated that age, body weight gender, genetics, and ethnicity play a role in this difference. ${ }^{[5-19]}$ In this study, we preferred using a tabular format to compare our study with earlier studies that employed a similar working methodology (Table 3). Our study results were comparable to those of the studies conducted in the Iraqi population. There were significant differences between the findings of the Indian population and our findings. ${ }^{[5]}$ This difference also applies to other studies in Table 3. This difference may be attributable to smaller body surface area of Indians, and in general, Asians. ${ }^{[5]}$ Nevertheless, the similarities between our study and the Iraqi study ${ }^{[20]}$ may be due to racial and genetic factors, body habitus, environmental factors and life style. The findings of our study were also notably comparable to those of studies conducted in USA. ${ }^{[10,14,19]}$ To investigate the effect of ethnic origin on coronary artery diameters, Lip et al. ${ }^{[6]}$ compared coronary artery diameters of subjects of Indian origin with those of English origin both living in the UK, and found that the latter group had smaller coronary artery diameters. A study by Brister et al. ${ }^{[1]}$ in Southern Asians concluded that ethnicity was a cardiovascular risk factor. Palaniappan et al. found that African-Americans, AsianAmericans and Indian-Americans were higher-risk groups for coronary artery disease. ${ }^{[12]}$ Likewise, Ranjith et al. ${ }^{[13]}$ demonstrated a relationship between demographics and acute coronary syndrome.

Larger LAD diameters observed in men indicate that gender is a factor for coronary artery diameter. A key observation of most angiographic procedures involving coronary artery diameters is that women have smaller

\section{Table 1}

Mean values (mean \pm standard deviation) of coronary artery lumen diameter according to gender.

\begin{tabular}{lcccc}
\hline & Male & Female & Total & $\mathbf{p}$ \\
\hline LMCA & $4.59 \pm 0.86$ & $4.35 \pm 0.69$ & $4.43 \pm 0.76$ & 0.255 \\
LAD & $3.63 \pm 0.51$ & $3.40 \pm 0.52$ & $3.48 \pm 0.53$ & 0.034 \\
CX & $3.29 \pm 0.67$ & $3.01 \pm 0.66$ & $3.11 \pm 0.67$ & $0.083^{*}$ \\
RCA & $3.55 \pm 0.46$ & $3.40 \pm 0.52$ & $3.45 \pm 0.5$ & 0.159 \\
\hline
\end{tabular}

${ }^{\star} p>0.05$ 
Table 2

Mean values (mean \pm standard deviation) of coronary artery lumen diameter according to the decades.

\begin{tabular}{lcccccc}
\hline Decade & $\mathbf{4}$ & $\mathbf{5}$ & $\mathbf{6}$ & $\mathbf{7}$ & $\mathbf{8}$ & $\mathbf{p}$ \\
\hline LMCA & $4.51 \pm 0.65$ & $4.41 \pm 0.7$ & $4.69 \pm 0.97$ & $4.27 \pm 0.49$ & $4.21 \pm 0.89$ & 0.503 \\
LAD & $3.69 \pm 0.5$ & $3.55 \pm 0.51$ & $3.49 \pm 0.73$ & $3.32 \pm 0.38$ & $3.6 \pm 0.46$ & 0.329 \\
CX & $2.89 \pm 0.49$ & $3.52 \pm 0.43$ & $3.18 \pm 0.59$ & $2.89 \pm 0.8$ & $2.83 \pm 0.64$ & $0.008^{*}$ \\
RCA & $3.53 \pm 0.43$ & $3.46 \pm 0.56$ & $3.44 \pm 0.49$ & $3.42 \pm 0.54$ & $3.16 \pm 0.49$ & 0.973 \\
\hline${ }^{*} p>0.05$ & & & & & &
\end{tabular}

coronary artery diameters compared to men. ${ }^{[8,9,14]}$ Hormonal factors are presumably the basis for genderdifferentiated diameter of coronary arteries. ${ }^{[15,16]}$ Although coronary artery diseases are more frequent in men than women, this is more attributable to other disease risk factors rather than the diameters. ${ }^{[21]}$ Nevertheless, poorer prognosis of cardiovascular events in women was associated with women who had smaller coronary artery diameters compared to men. ${ }^{[16]}$ These differences between men and women are important diagnostic, therapeutic and prognostic factors for patients. Patient-specific factors such as physical activity may also cause larger coronary artery size. ${ }^{[22]}$

Smaller coronary artery diameters may be considered as a risk factor for atherosclerosis. Also, atheroma can hemodynamically exacerbate disease severity with small- er vs larger coronary artery diameters. The role of coronary artery diameter size in the development of atherosclerosis remains unclear. However, coronary artery diameter size is known to influence hemodynamics. Hemodynamic factors such as increased blood flow, blood flow velocity or shear stress can either suppress atherogenesis or facilitate its development. Previous studies demonstrated that larger coronary arteries had both a higher flow velocity and higher flow volume, suggesting that increased blood flow and high flow velocity may suppress atherogenesis. ${ }^{[23-26]}$ Acute occlusion related to LAD lesions have a higher hospital mortality rate. ${ }^{[26,27]}$ A smaller coronary artery diameter adds to the technical challenges of the therapeutic intervention in procedures such as percutaneous transluminal coronary angioplasty, stents and atherectomy. ${ }^{[7]}$ Cardiac surgeons are therefore

Table 3

Comparison of the findings of our study in a Turkish population with previous studies from other parts of the world. Values are mean \pm standard deviation

\begin{tabular}{lcccccc}
\hline Population & $\mathbf{n}$ & Gender & LMCA & LAD & Cx & RCA \\
\hline Turkish (Our study) & 26 & Male & $4.59 \pm 0.8$ & $3.63 \pm 0.5$ & $3.29 \pm 0.6$ & $3.55 \pm 0.4$ \\
& 51 & Female & $4.35 \pm 0.6$ & $3.40 \pm 0.5$ & $3.01 \pm 0.6$ & $3.40 \pm 0.5$ \\
USA $^{[10]}$ & 60 & Male & $4.5 \pm 0.5$ & $3.6 \pm 0.5$ & $3.4 \pm 0.5$ & $3.9 \pm 0.6$ \\
& 10 & Female & $3.9 \pm 0.4$ & $3.2 \pm 0.5$ & $2.9 \pm 0.6$ & $3.3 \pm 0.6$ \\
USA $^{[14]}$ & 19 & Male & $4.3 \pm 0.6$ & $3.5 \pm 0.5$ & $3.1 \pm 0.7$ & $3.4 \pm 0.7$ \\
& 7 & Female & $3.5 \pm 0.7$ & $2.9 \pm 0.4$ & $2.6 \pm 0.6$ & $3 \pm 0.5$ \\
USA $^{[19]}$ & 55 & Male & $4.7 \pm 0.7$ & $3.7 \pm 0.6$ & $3.6 \pm 0.6$ & $3.8 \pm 0.8$ \\
& 90 & Female & $4.2 \pm 0.6$ & $3.3 \pm 0.5$ & $3.0 \pm 0.5$ & $3.3 \pm 0.6$ \\
Indian[i5] $^{[1]}$ & 61 & Male & $3.72 \pm 0.6$ & $2.85 \pm 0.6$ & $2.82 \pm 0.6$ & $2.75 \pm 0.6$ \\
Iraqi $^{[20]}$ & 33 & Female & $3.40 \pm 0.6$ & $2.72 \pm 0.5$ & $2.68 \pm 0.6$ & $2.55 \pm 0.6$ \\
Asian-Indian $^{[32]}$ & 32 & Male & $4.86 \pm 0.77$ & $3.60 \pm 0.58$ & $3.26 \pm 0.62$ & $3.26 \pm 0.65$ \\
& 56 & Female & $4.50 \pm 0.73$ & $3.31 \pm 0.46$ & $3.03 \pm 0.39$ & $3.02 \pm 0.55$ \\
Caucasian $^{[19]}$ & 68 & Male & 4.1 & 3.1 & 3 & 3.3 \\
Asian $^{[19]}$ & 81 & Female & 3.9 & 3.1 & 3 & 2.9 \\
Japan $^{[3]]}$ & 53 & Male & $4.5 \pm 0.9$ & $3.0 \pm 0.6$ & $2.8 \pm 0.6$ & $3.8 \pm 0.8$ \\
Pakistani $^{[7]}$ & 53 & Male & $4.6 \pm 0.9$ & $2.8 \pm 0.6$ & $2.9 \pm 0.8$ & $3.5 \pm 0.8$ \\
\hline & 7 & Male & $5.07 \pm 0.75$ & $3.3 \pm 0.85$ & $3.53 \pm 0.76$ & $3.61 \pm 0.58$ \\
& 220 & - & 4.28 & 3.22 & 3.02 & 3.08 \\
\hline
\end{tabular}


advised to take coronary artery diameter into consideration in their practice.

A statistically significant correlation between certain coronary artery diameters was demonstrated. For the relationship between coronary artery diameter and age, a significantly weak and negative correlation between $\mathrm{Cx}$ diameter and age was noted. There was no association between age and other coronary artery diameters. Dodge et al. ${ }^{[9]}$ and MacAlphin et al. ${ }^{[14]}$ also failed to establish a relationship between age and coronary artery diameter. The mechanism by which aging affects the coronary artery size can not be conclusively elucidated. Arteries may be expanding with age, as they become diffusely narrower with progressive intimal disease. The internal diameter may be larger or smaller depending on the prevailing effect. With aging, the increase in intimal thickness is offset by the histological increase in the internal diameter. This may be the result of adapting to thickening due to aging, and not as a result of the effects of aging on the arterial wall. ${ }^{[2]}$

Coronary artery diameter is a key determinant for cardiologic pathologies and often related with the clinical status. ${ }^{[2,30]}$ As an example, vessels with a diameter smaller than $2.5 \mathrm{~mm}$ are more likely to show occlusion or thrombosis. ${ }^{[7]}$ Although coronary artery diameter is known to be affected by physiological and pathological conditions, the number of published studies investigating coronary artery diameters in individuals without coronary artery pathologies are very few.

\section{Conclusion}

The findings of this study will not only contribute to the diagnosis and treatment of patients, but they will add to the global data pool on the subject. These studies may be further improved by the addition of other parameters and enrollment of patients from other regions of the country. We therefore believe that our study will also provide a basis for similar studies to build on.

\section{References}

1. Onat A, Dursunoğlu D, Bulur S, Küçükdurmaz Z, Kaya Z, Ordu S, Uğur M. Turkish Adult Risk Factor Survey 2007: decline in all-cause and coronary mortality. [Article in Turkish] Turk Kardiyol Dern Ars 2008;36:77-81.

2. Sans S, Kesteloot H, Kromhout D. The burden of cardiovascular diseases mortality in Europe. Task Force of the European Society of Cardiology on Cardiovascular Mortality and Morbidity Statistics in Europe. Eur Heart J 1997; 18:1231-48.

3. O'Connor NJ, Morton JR, Birkmeyer JD, Olmstead EM, O'Connor GT. Effect of coronary artery diameter in patients undergoing coronary bypass surgery. Northern New England Cardiovascular Disease Study Group. Circulation 1996;93:652-5.
4. Moore KL Dalley AF. Clinically oriented anatomy. 4th ed. Lewiston (NY): Lippicott Williams and Wilkins; 1999.

5. Saikrishna C, Talwar S, Gulati G, Kumar AS. Normal coronary artery dimensions in Indians. Indian Journal of Thoracic and Cardiovascular Surgery 2006;22:159-64.

6. Lip GY, Rathore VS, Katira R, Watson RD, Singh SP. Do IndoAsians have smaller coronary arteries? Postgrad Med J 1999;75:463-6.

7. Kaimkhani Z, Ali M, Faruqui AM. Coronary artery diameter in a cohort of adult Pakistani population. J Pak Med Assoc 2004;54:25861.

8. Yang F, Minutello RM, Bhagan S, Sharma A, Wong SC. The impact of gender on vessel size in patients with angiographically normal coronary arteries. J Interv Cardiol 2006;19:340-4.

9. Dodge JT Jr, Brown BG, Bolson EL, Dodge HT. Lumen diameter of normal human coronary arteries. Influence of age, sex, anatomic variation, and left ventricular hypertrophy or dilation. Circulation 1992;86:232-46.

10. Leung WH, Stadius ML, Alderman EL. Determinants of normal coronary artery dimensions in humans. Circulation 1991;84:2294306.

11. Brister SJ, Hamdulay Z, Verma S, Maganti M, Buchanan MR. Ethnic diversity: South Asian ethnicity is associated with increased coronary artery bypass grafting mortality. J Thorac Cardiovasc Surg 2007;133:150-4.

12. Palaniappan L, Wang Y, Fortmann SP. Coronary heart disease mortality for six ethnic groups in California, 1990-2000. Ann Epidemiol 2004;14:499-506.

13. Ranjith N, Pegoraro RJ, Naidoo DP. Demographic data and outcome of acute coronary syndrome in the South African Asian Indian population. Cardiovasc J S Afr 2005;16:48-54.

14. MacAlpin RN, Abbasi AS, Grollman JH Jr, Eber L. Human coronary artery size during life. A cinearteriographic study. Radiology 1973;108:567-56.

15. Gilligan DM, Quyyumi AA, Cannon RO 3rd. Effects of physiological levels of estrogen on coronary vasomotor function in postmenopausal women. Circulation 1994;89:2545-51.

16. Herity NA, Lo S, Lee DP, Ward MR, Filardo SD, Yock PG, Fitzgerald PJ, Hunt SA, Yeung AC. Effect of a change in gender on coronary arterial size: a longitudinal intravascular ultrasound study in transplanted hearts. J Am Coll Cardiol 2003;41:1539-46.

17. Goldman S, Zadina K, Moritz T. Long-term patency of saphenous vein and left internal mammary artery grafts after coronary artery bypass surgery: results from a Department of Veterans Affairs Cooperative Study. J Am Coll Cardiol 2004;44:2149-56.

18. Ilayperuma I, Nanayakkara, BG, Palahepitiya KN. Sexual differences in the diameter of coronary arteries in an adult Sri Lankan population. Int J Morphol 2011;29:1444-8.

19. Zindrou D, Taylor KM, Bagger JP. Coronary artery size and disease in UK South Asian and Caucasian men. Eur J Cardiothorac Surg 2006;29:492-5.

20. Shukri IG, Hawas JM, Karim SH, Ali IKM. Angiographic study of the normal coronary artery in patients attending Ulaimani Center for Heart Diseases. European Scientific Journal 2014;10:384-415.

21. McKinlay JB. Some contributions from the social system to gender inequalities in heart disease. J Health Soc Behav 1996;37:1-26.

22. Rose G, Prineas RJ, Mitchell JR. Myocardial infarction and the intrinsic calibre of coronary arteries. Br Heart J 1967;29:548-52.

23. Zarins CK, Bomberger RA, Glagov S. Local effects of stenoses: increased flow velocity inhibits atherogenesis. Circulation 1981;64: 221-7. 
24. Asakura T, Karino T. Flow patterns and spatial distribution of atherosclerotic lesions in human coronary arteries. Circ Res 1990; 66:1045-66.

25. Gibson CM, Diaz L, Kandarpa K, Sacks FM, Pasternak RC, Sandor T, Feldman C, Stone PH. Relation of vessel wall shear stress to atherosclerosis progression in human coronary arteries. Arterioscler Thromb 1993;13:310-5.

26. Arnold AM, Mick MJ, Piedmonte MR, Simpfendorfer C. Gender differences for coronary angioplasty. Am J Cardiol 1994;74:18-21.

27. Bell MR, Holmes DR, Berger PB, Garratt KN, Bailey KR, Gersh BJ. The changing in- hospital mortality of women undergoing percutaneous transluminal coronary angioplasty. JAMA 1993;269:2091-5.

28. Glagov S, Weisenberg E, Zarins CK, Stankunavicius R, Kolettis GJ. Compensatory enlargement of human atherosclerotic coronary arteries. N Engl J Med 1987;316:1371-5.

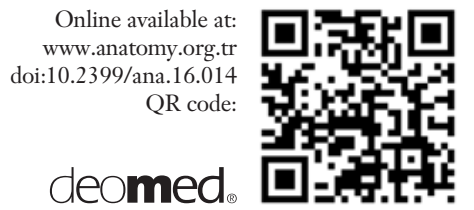

29. Wilens SL, Plair CM, Henderson D. Size of the major epicardial coronary arteries at necropsy. Relation to age, weight and myocardial infarction. JAMA 1966;198:1325-9.

30. Schunkert H, Harrell L, Palacios IF. Implications of small reference vessel diameter in patients undergoing percutaneous coronary revascularization. J Am Coll Cardiol 1999;34:40-8.

31. Makaryus AN, Dhama B, Raince J, Raince A, Garyali S, Labana SS, Kaplan BM, Park C, Jauhar R. Coronary artery diameter as a risk factor for acute coronary syndromes in Asian-Indians. Am J Cardiol 2005;96:778-80.

32. Funabashi N, Kobayashi Y, Perlroth M, Rubin GD. Coronary artery: quantitative evaluation of normal diameter determined with electron-beam CT compared with cine coronary angiography. Radiology 2003;226:263-71.

Correspondence to: Ozan Turamanlar, MD, PhD Department of Anatomy, Faculty of Medicine, Afyon Kocatepe University, Afyonkarahisar, Turkey Phone: +902724440303

e-mail: ozanturamanlar@hotmail.com

Conflict of interest statement: No conflicts declared.

This is an open access article distributed under the terms of the Creative Commons Attribution-NonCommercial-NoDerivs 3.0 Unported (CC BY-NCND3.0) Licence (http://creativecommons.org/licenses/by-nc-nd/3.0/) which permits unrestricted noncommercial use, distribution, and reproduction in any medium, provided the original work is properly cited. Please cite this article as: Turamanlar O, Adalı F, Beker Acay M, Horata E, Tor O, Macar O, Keş H, Keskin H, Abbasoğlu Y. Angiographic analysis of normal coronary artery lumen diameter in a Turkish population. Anatomy 2016;10(2):99-104. 